\title{
Coronary haemodynamics in left ventricular hypertrophy
}

\author{
David R Wallbridge, Stuart M Cobbe
}

\begin{abstract}
Background-Left ventricular hypertrophy is associated with an increased risk of cardiovascular morbidity and mortality. Previous studies have shown that patients with left ventricular hypertrophy develop electrocardiographic changes and left ventricular dysfunction during acute hypotension, and suggest that the lower end of autoregulation may be shifted upwards.
\end{abstract}

Aim-To measure coronary blood flow (velocity) and flow reserve during acute hypotension in patients with left ventricular hypertrophy.

Patients-Eight patients with atypical chest pain and seven with hypertensive left ventricular hypertrophy; all with angiographically normal epicardial vessels.

Setting-Tertiary referral centre.

Methods-The physiological range of blood pressure was determined by previous ambulatory monitoring. Left ventricular mass was determined by echocardiography. At cardiac catheterisation, left coronary blood flow velocity was measured using a Judkins style Doppler tipped catheter. During acute hypotension with sodium nitroprusside, coronary blood flow velocity was recorded at rest and during maximal hyperaemia induced by intracoronary injection of adenosine. Quantitative coronary angiography was performed manually.

Results-For both groups coronary blood flow velocity remained relatively constant over a range of physiological diastolic blood pressures and showed a steep relation with diastolic blood pressure during maximal hyperaemia with intracoronary adenosine. Absolute coronary blood flow (calculated from quantitative angiographic data), standardised for left ventricular mass, showed reduced flow in the hypertensive group at rest and during maximal vasodilatation.

Conclusion-The results are consistent with an inadequate blood supply to the hypertrophied heart, but no upward shift of the lower end of the autoregulatory range was observed.

(Heart 1996;75:369-376)

Keywords: left ventricular hypertrophy; coronary blood flow; hypotension

The clinical suspicion that the hypertrophied heart has an inadequate coronary circulation is supported by the frequent observation that patients with arterial hypertension have angina pectoris and manifest an abnormal exercise test ${ }^{1}$ or thallium scan $^{2}$ even in the absence of angiographic coronary artery disease. The pathophysiological background to this is considered to be increased coronary vascular resistance and a reduced coronary reserve. ${ }^{345}$ Indeed, the segmental perfusion defects seen during thallium scintigraphy may be explained by differences in coronary reserve between major epicardial vessels. ${ }^{6}$ Changes in coronary reserve are due to the complex interaction of changes in vessel structure, ${ }^{7}$ distribution of microvascular resistance, ${ }^{8}$ and endothelial function. ${ }^{910}$ Extravascular compressive forces have only a minor role. ${ }^{11}$

Attempts to lower coronary heart disease mortality in various long-term and large-scale trials of antihypertensive treatment have been disappointing. ${ }^{12}$ For patients with pre-existing ischaemic heart disease, a J shaped relation is apparent between the frequency of death from myocardial infarction and treated diastolic blood pressure. This, together with observations of continuous blood pressure monitoring, led Floras ${ }^{13}$ to conclude that the normal fall in nocturnal pressure might be exaggerated by antihypertensive therapy to a level where autoregulation fails and myocardial ischaemia occurs. Acute hypotension in patients with left ventricular hypertrophy is associated with electrocardiographic (ECG) $T$ wave changes ${ }^{14}$ and left ventricular dysfunction in the presence of coronary artery disease. ${ }^{15}$ More direct evidence for an upward shift in the lower end of the autoregulatory range is available from coronary sinus thermodilution studies. ${ }^{16}$ In patients with hypertensive left ventricular hypertrophy, coronary sinus blood flow started to decline and myocardial $\mathrm{O}_{2}$ extraction started to rise at perfusion pressures of $90-80 \mathrm{~mm} \mathrm{Hg}$. Confirmation of this observation would have important practical implications for the assessment and treatment of patients with hypertensive left ventricular hypertrophy.

Our aim was, therefore, to measure coronary blood flow (velocity) and coronary flow reserve during acute hypotension in patients with left ventricular hypertrophy.

\section{Patients and methods}

PATIENTS

Patients were recruited from the Hypertension Clinic of the Glasgow Royal Infirmary on the basis of ECG evidence of left ventricular hypertrophy and strain. Invasive studies were considered to be justified in this group on the basis of the poor prognosis associated with this 
ECG pattern. The controls were recruited from the routine waiting list for cardiac catheterisation. All these patients required coronary angiography for a diagnosis of chest pain, and were considered to have either atypical symptoms or normal/equivocal non-invasive tests for coronary artery disease. Patients continued their usual medication up to and during the study. Exclusion criteria were a history of overt cerebrovascular disease (previous stroke or transient ischaemic attack), significant carotid artery stenosis demonstrated on Doppler examination, diabetes mellitus, and treatment with dipyridamole or theophyllines, unless these drugs had been previously stopped.

\section{ELECTROCARDIOGRAPHY}

The resting 12 lead ECGs were recorded with the Glasgow Computer Assisted Reporting of Electrocardiograms system. ${ }^{17}{ }^{18}$ Electrocardiographic left ventricular hypertrophy and strain was defined as occurring when there were repolarisation abnormalities (ST depression of $\geqslant 0.02 \mathrm{mV}$ and $\mathrm{T}$ wave inversion of $0.1 \mathrm{mV}$ or more in $1, \mathrm{aVL}, \mathrm{v} 5$, or V6) in the presence of voltage criteria for left ventricular hypertrophy $(\mathrm{SV} 1+\mathrm{RV} 5 \geqslant 3.5 \mathrm{mV})$

\section{ECHOCARDIOGRAPHY}

Measurements of wall thickness and internal ventricular dimensions were made according to the recommendations of the American Society of Echocardiography ${ }^{19}$ with modifications of the Penn convention. ${ }^{20}$ Left ventricular mass index was determined by the method of Devereux et $a l,{ }^{21}$ and fractional shortening calculated by the method of McDonald et al. ${ }^{22}$ End diastolic relative wall thickness, calculated as the ratio of posterior wall thickness to one half left ventricular internal diameter, was used to categorise patients with increased left ventricular mass as having either concentric (end diastolic relative wall thickness $\geqslant 0.45$ ) or eccentric hypertrophy (end diastolic relative wall thickness < 0.45). ${ }^{23}$ Meridional end systolic wall stress $(\sigma)\left(\right.$ dynes $\left./ \mathrm{cm}^{2}\right)$ was calculated as an indirect measure of myocardial oxygen consumption, using the equation:

$$
\sigma=\frac{0 \cdot 334^{\star} \mathrm{P}^{\star} \text { LVIDs }}{\mathrm{h}^{\star}\left(1+\frac{\mathrm{h}}{\text { LVIDs }}\right)}
$$

where $P$ is peak systolic pressure $(\mathrm{mm} \mathrm{Hg}$ ) (which, in the absence of left ventricular outflow obstruction and severe mitral regurgitation, is close to end systolic pressure), LVIDs is the left ventricular internal diameter at end systole $(\mathrm{cm})$; and $\mathrm{h}$ is the mean thickness of the interventricular septum and posterior wall (cm). ${ }^{24}$ Meridional end diastolic wall stress was similarly calculated.

AMBULATORY BLOOD PRESSURE MONITORING The diurnal range of blood pressures for each participant was measured by a $24 \mathrm{~h}$ intermittent non-invasive blood pressure recording using an oscillometric method (Spacelabs 90207). ${ }^{25}$
CAROTID DUPLEX SCANNING

Carotid artery disease was excluded in all patients by Doppler colour flow examination performed by an experienced operator.

\section{THALLIUM SCINTIGRAPHY}

Dynamic exercise was performed on a bicycle ergometer with $50 \mathrm{~W}$ increments in workload every $3 \mathrm{~min}$. At peak exercise $80 \mathrm{MBq}$ thallium-201 was injected and data acquired in list mode in three projections using a General Electric Maxicamera (Milwaukee, Wisconsin, USA) fitted with a low energy converging collimator. Redistribution images were obtained $4 \mathrm{~h}$ later in the same fashion. Analysis was by visual scoring of thallium uptake to the left ventricle. ${ }^{26}$

\section{CARDIAC CATHETERISATION}

Cardiac catheterisation was undertaken in the post-absorptive state, with oral diazepam (10 mg) sedation. Only patients without significant coronary artery disease proceeded to the coronary flow reserve study.

MEASUREMENT OF CORONARY FLOW RESERVE

In order to perform the Doppler studies, a femoral venous sheath was introduced, and a 6 French gauge temporary pacing wire positioned in the right atrium. A bolus injection of heparin 5000 units was administered intravenously. The 8 French gauge $4 \mathrm{~L}$ Judkins Doppler catheter (Cordis, Brentford, UK) ${ }^{27}$ was introduced and a satisfactory position in the left main stem artery confirmed by contrast injection. The phasic flow velocity signal was optimised by adjustment of the position of the tip of the catheter and by range gating the Doppler transducer (usually 2-4 $\mathrm{mm}$ from the tip) using a velocimeter (Millar Instruments, Houston, Texas, USA). Arterial blood pressure (recorded from the Doppler catheter), mean and phasic flow velocity, and ECG leads I, AVF, and V1 were continuously recorded on a Mingograf 7 (Siemens Elema, Erlangen, Germany) multichannel recorder. Pressure $(0-200 \mathrm{~mm} \mathrm{Hg})$ and flow velocity (0-100 $\mathrm{cm} / \mathrm{s}$ ) were electronically calibrated.

\section{EXPERIMENTAL PROTOCOL}

The study protocol involved assessment of Doppler flow velocity, and systemic haemodynamic and ECG variables in response to incremental intracoronary bolus injections of adenosine $(10,20,30$, and $40 \mu \mathrm{g}$ as a $6-8 \mathrm{ml}$ bolus over $2-3 \mathrm{~s}$ ), to ensure maximal pharmacological vasodilatation was achieved. ${ }^{28}$ Adenosine $(5 \mu \mathrm{g} / \mathrm{ml}$ in $0.9 \%$ saline $)$ was prepared by the Sterile Products Manufacturing Unit of this hospital. Variables were continuously recorded with a chart paper speed of 10 $\mathrm{mm} / \mathrm{s}$, with a fast paper speed of $100 \mathrm{~mm} / \mathrm{s}$ used at baseline and during peak hyperaemia. Cineangiography was undertaken at baseline and peak hyperaemia, using magnified views obtained in the 10 or $40^{\circ}$ left anterior oblique projections with $10 \mathrm{ml}$ of iopamidol delivered at $3 \mathrm{ml} / \mathrm{s}$ by a power injector.

Blood pressure was modified within the range of pressures defined by prior ambulatory 
monitoring. At each steady state blood pressure, variables were measured at baseline and peak hyperaemia, at the resting sinus rate and the atrial pacing rate of 100 beats $/ \mathrm{min}$. Blood pressure was increased by incremental peripheral infusion of phenylephrine $(1 \mathrm{mg}$ in $500 \mathrm{ml}$ $5 \%$ dextrose: dosage range $90-360 \mathrm{ml} / \mathrm{h}$ ) (three controls and three patients with hypertension) and reduced by incremental infusion of sodium nitroprusside $(50 \mathrm{mg}$ in $250 \mathrm{ml} \mathrm{5 \%}$ dextrose: dosage range $5-50 \mathrm{ml} / \mathrm{h}$ ) (all participants). The mean number of paired measurements of velocity/participant was $11.3(6 \cdot 6)$ in the control group and $14.4(3 \cdot 6)$ in the hypertensive group.

The protocol was subsequently modified to permit assessment of the effects of sodium nitroprusside on the coronary circulation. Sodium nitroprusside was administered by intracoronary infusion at a rate of $100 \mathrm{ml} / \mathrm{h}$ in incremental concentrations of $0 \cdot 1,1$, and 10 $\mathrm{mg} / \mathrm{l}$. After each dose had been infused for 2 min, coronary blood flow velocity was recorded at a paper speed of $100 \mathrm{~mm} / \mathrm{s}$ and cineangiography was undertaken.

\section{QUANTITATIVE CORONARY ANGIOGRAPHY}

The studies of acute hypotension and coronary flow reserve involved the administration of potent vasodilators. To equate changes in Doppler velocity with changes in coronary blood flow, it was important to assess the effects of adenosine and sodium nitroprusside on the size of the proximal left coronary system distal to the tip of the Doppler catheter. A cardiac catheterisation laboratory with digital acquisition and quantitative coronary angiography was not available for the duration of this study. Therefore, appropriate $35 \mathrm{~mm}$ still frames, showing the proximal left coronary system in magnification, were spliced from the cine film and these slides were then projected onto a $2 \mathrm{~m}$ wide screen from a distance of 5.5 $\mathrm{m}$. The luminal diameter of the left main coronary artery $2 \mathrm{~mm}$ distal to the catheter tip was measured manually using callipers. The Doppler catheter, of known external diameter $2.67 \mathrm{~mm}$, was used as a reference. The reproducibility of this technique was assessed by repeated measurements. At baseline blood pressure, the technique was used to assess vasodilatation induced by intracoronary injec- tion of adenosine and sodium nitroprusside as an intracoronary infusion. Assuming a circular cross sectional (CS) shape of the left main stem coronary artery, and linear blood flow velocity (BFV) across it, coronary blood flow $(\mathrm{ml} / \mathrm{min})$ may be calculated as:

$$
\text { Flow }=\mathrm{CS} \text { area }\left(\pi \times \text { radius }^{2}\right) \times \mathrm{BFV}
$$

\section{STATISTICAL ANALYSIS}

When comparing two groups of data an estimate was made of the distribution by constructing histograms. If the data were normally distributed a two sample $t$ test was employed. When the distribution was skewed, the nonparametric Mann-Whitney $U$ or KruskalWallis tests were used. The inter-relation between variables was assessed by the correlation coefficient if the data were normally distributed and by Spearman's rank test if the data were skewed. The repeatability of a test was assessed by techniques described by Bland and Altman. ${ }^{29}$ Group values are expressed as means (SD). For all analyses $P<0.05$ was considered significant.

ETHICAL APPROVAL

This study was approved by the Ethical Committee of Glasgow Royal Infirmary. Written informed consent was obtained for invasive studies.

\section{Results}

PATIENTS

Table 1 lists the demographic details of patients included in the study. There was a trend for patients with hypertensive left ventricular hypertrophy to be older than the control group. Raised blood pressure had been documented for a mean of $10 \cdot 1$ years in the hypertensive group. While all the patients in the control group required coronary angiography for the diagnosis of chest pain, a history of either typical angina or exertional dyspnoea could be elicited in all but one of the patients with hypertension. No patient included in the study had evidence of previous myocardial infarction. The principal reasons for exclusion from the study were asymptomatic carotid artery disease (five patients) and significant coronary artery disease at coronary angiogra-

Table 1 Demographic and echocardiographic data

\begin{tabular}{|c|c|c|c|c|}
\hline & \multirow[b]{2}{*}{ Controls } & \multicolumn{3}{|c|}{ Patients with hypertensive $L V H$} \\
\hline & & All patients & $\begin{array}{l}\text { Concentric } \\
L V H\end{array}$ & $\begin{array}{l}\text { Eccentric } \\
\text { LVH }\end{array}$ \\
\hline $\begin{array}{l}\text { n } \\
\text { Mean (SD) age (years) } \\
\text { Sex (M/F) } \\
\text { LVIDd (mm) } \\
\text { IVS (mm) } \\
\text { PWT (mm) } \\
\text { Fractional shortening (\%) } \\
\text { LV mass (g) } \\
\text { LV mass index (g/m²) } \\
\text { Relative wall thickness } \\
\text { LV wall stress (systole) }\left(\times 10^{3} \mathrm{dyn} / \mathrm{cm}^{2}\right) \\
\text { LV wall stress (diastole) }\left(\times 10^{3} \mathrm{dyn} / \mathrm{cm}^{2}\right)\end{array}$ & $\begin{array}{c}8 \\
46 \cdot 1(5 \cdot 2) \\
5 / 3 \\
4 \cdot 7(0 \cdot 2) \\
1 \cdot 1(0 \cdot 1) \\
1 \cdot 0(0 \cdot 2) \\
31 \cdot 9(3 \cdot 9) \\
211 \cdot 5(49 \cdot 8) \\
106 \cdot 3(19 \cdot 4) \\
0 \cdot 44(0 \cdot 10) \\
85 \cdot 5(30 \cdot 1) \\
13 \cdot 0(3 \cdot 8)\end{array}$ & $\begin{array}{l}7 \\
52 \cdot 5(5 \cdot 8) \\
4 / 3 \\
5 \cdot 1(1 \cdot 6) \dagger \\
1 \cdot 7(0 \cdot 3) \ddagger \\
1 \cdot 4(0 \cdot 2) \dagger \\
36 \cdot 8(11 \cdot 4) \\
409 \cdot 2(144 \cdot 2) \dagger \\
209 \cdot 9(55 \cdot 3) \ddagger \\
0 \cdot 59(0 \cdot 21) \\
68 \cdot 2(46 \cdot 5) \\
16 \cdot 2(15 \cdot 0)\end{array}$ & $\begin{array}{l}5 \\
50 \cdot 9(6 \cdot 3) \\
2 / 3 \\
4 \cdot 2(0 \cdot 5) \\
1 \cdot 8(0 \cdot 3)^{\star} \\
1 \cdot 4(0 \cdot 2)^{\star} \\
42 \cdot 0(7 \cdot 9)^{\star} \\
343 \cdot 3(110 \cdot 4)^{\star} \\
182 \cdot 1(34 \cdot 3)^{\star} \\
0 \cdot 69(0 \cdot 14) \dagger \\
41 \cdot 6(7 \cdot 6)^{\star} \\
8 \cdot 5(2 \cdot 7)\end{array}$ & $\begin{array}{l}2 \\
55 \cdot 4(52 \cdot 1,58 \cdot 7) \\
2 / 0 \\
7 \cdot 3(7 \cdot 0,7 \cdot 6)^{\star} \\
1 \cdot 4(1 \cdot 3,1 \cdot 4)^{\star} \\
1 \cdot 2(1 \cdot 1,1 \cdot 3) \\
23 \cdot 8(28 \cdot 9,18 \cdot 5)^{\star} \\
574 \cdot 0(569 \cdot 5,578 \cdot 5)^{\star} \\
279 \cdot 4(272 \cdot 5,286 \cdot 4)^{\star} \\
0 \cdot 33(0 \cdot 29,0 \cdot 37) \\
134 \cdot 6(120 \cdot 6,148 \cdot 7) \\
31 \cdot 6(45 \cdot 6,17 \cdot 4)^{\star}\end{array}$ \\
\hline
\end{tabular}


phy (three). Treatment in the control group comprised calcium channel blockers $(n=6)$, $\beta$ blockers $(n=4)$, and nitrates $(n=5)$, but not angiotensin converting enzyme inhibitors or diuretics. By comparison, treatment in the hypertensive group included calcium channel blockers $(n=3), \beta$ blockers $(n=3)$, angiotensin converting enzyme inhibitors $(n=4)$, and diuretics $(n=3)$, but not nitrates.

\section{BLOOD PRESSURE}

Despite the continuation of antihypertensive treatment, blood pressure was higher in the hypertensive group, whether measured at rest on admission (systolic: 158.7 (13.5) $v 130.0$ $(22.8) \mathrm{mm} \mathrm{Hg}, \quad \mathrm{P}=0.032$; diastolic: 96.6 $(10.1) v 79.0(10.9), \mathrm{P}=0.015)$ or at cardiac catheterisation (systolic: $168.0(15.4) v 137.5$ (23.6), not significant; diastolic: $90 \cdot 4(17 \cdot 1) v$ 78.8 (19.4), not significant). Ambulatory blood pressure monitoring (a mean of 43 recordings $/ 24 \mathrm{~h} /$ patient) showed significantly greater mean hourly systolic (at 5-12 and 24 $\mathrm{h}$ ) and diastolic (at 6-8 and $24 \mathrm{~h}$ ) pressures in the hypertensive group (fig 1). Mean ambulatory pressures were higher in the hypertensive group (systolic: 142.4 (16.3) v 122.7 (18.7), $\mathrm{P}<0.0001$; diastolic: $86.4(12.9) \quad v \quad 73.9$ $(12 \cdot 0), \mathrm{P}<0.0001)$.

\section{LEFT VENTRICULAR MASS INDEX}

Echocardiography of all patients in the hypertensive group showed left ventricular hypertrophy, with measures of interventricular septal thickness, left ventricular mass, and left ventricular mass index significantly greater than in the control group (table 1).

\section{THALLIUM SCINTIGRAPHY}

Of the eight patients in the control group, one showed a fixed anteroseptal and two a small fixed apical defect. In none of these patients was there evidence of reversible perfusion defects. All patients in the hypertensive group showed fixed thallium defects, with additional reversible perfusion defects in three when reimaged at $4 \mathrm{~h}$. Scintigraphy showed gross hypertrophy in four patients, and left ventricular dilatation with global hypokinesia in two.

\section{CARDIAC CATHETERISATION}

Left ventricular end diastolic pressure before ventriculography was not significantly different between the two groups (hypertensive 14.5 $(5 \cdot 8) v$ control $10 \cdot 6(2 \cdot 1) \mathrm{mm} \mathrm{Hg})$. Contrast

Figure 1 Mean $24 \mathrm{~h}$ ambulatory systolic and diastolic blood pressure (BP) for the hypertensive left ventricular hypertrophy $(\mathrm{LVH})$ and control (LVH) and control
groups. $\star P<0.05, L V H$ groups. ${ }^{\star} P<0 \cdot 05, L V$
versus controls, MannWhitney U test.

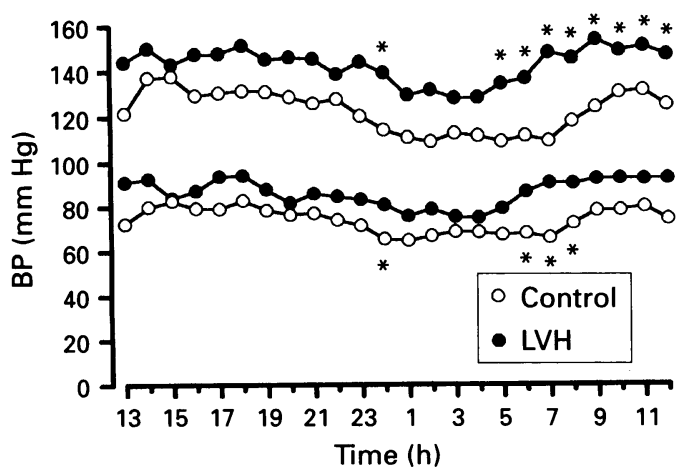

ventriculography showed normal ventricular function in all but the two patients with hypertension and evidence of left ventricular dilatation and global dysfunction. Coronary angiography, by definition, showed no evidence of significant stenosis (> $50 \%$ diameter) in the left main stem, left anterior descending, or circumflex coronary arteries in patients in whom coronary flow studies were undertaken. No participants developed either angina or ST segment depression as a consequence of lowering of blood pressure.

CORONARY BLOOD FLOW VELOCITY

Figure 2 shows the relation between coronary blood flow velocity and diastolic blood pressure for the control group. Overall, coronary blood flow velocity at rest appears to be relatively constant over a range of diastolic pressures (gradient $0.08 \mathrm{~cm} / \mathrm{s} / \mathrm{mm} \mathrm{Hg}$ ), consistent with the concept of autoregulation. In contrast, coronary blood flow velocity during peak hyperaemia induced by intracoronary adenosine is strongly dependent on diastolic blood pressure (gradient $0.39 \mathrm{~cm} / \mathrm{s} / \mathrm{mm} \mathrm{Hg}$ ).

For comparison, fig 3 shows the relation between coronary blood flow velocity and diastolic blood pressure for the hypertensive group. Under resting conditions, coronary blood flow velocity seems relatively independent of diastolic blood pressure and quantita-

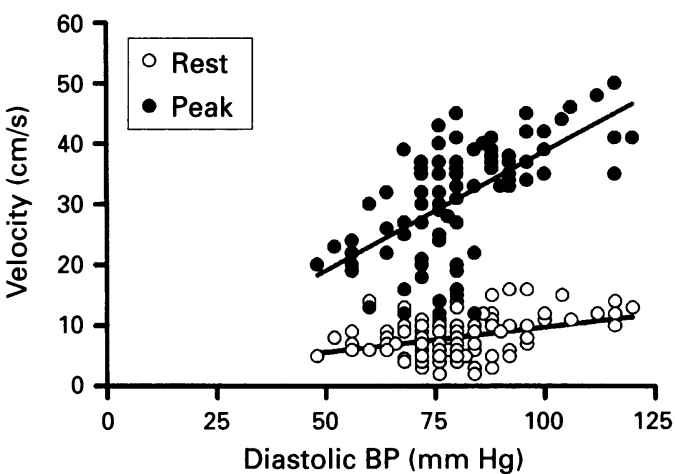

Figure 2 Relation between diastolic blood pressure (DBP) and coronary blood flow velocity (CBFV) in the control group. Paired observations were made at rest $\left(C B F V=1.38+0.0839^{\star} D B P, r=0.355, P<0.001\right)$ and during maximal hyperaemia (peak) (CBFV $=0.52$ $\left.+0.393^{\star} D B P, r=0.635, P<0.001\right)$.

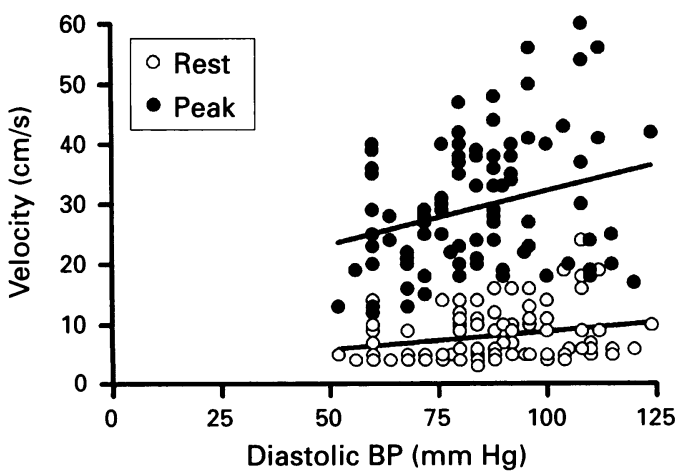

Figure 3 Relation between diastolic blood pressure $(D B P)$ and coronary blood flow velocity (CBFV) in the hypertensive group. Paired observations were made at rest $(C B F V=2.85+0.061 * D B P, r=0.235, P<0.05)$ and during maximal hyperaemia (peak) (CBFV $=14.3$ $+0 \cdot 179 \star D B P, r=0.279, P<0.01)$ 
tively similar to that in the control group (gradient $0.06 \mathrm{~cm} / \mathrm{s} / \mathrm{mm} \mathrm{Hg}$ ). During controlled hypotension, no threshold or critical diastolic blood pressure could be determined. Peak coronary blood flow velocity was strongly determined by diastolic blood pressure (gradient $0.18 \mathrm{~cm} / \mathrm{s} / \mathrm{mm} \mathrm{Hg}$ ). The slope of the coronary blood flow velocity/diastolic blood pressure relation was less steep in the hypertrophy group than in controls $(0.18 v 0.39$ $\mathrm{cm} / \mathrm{s} / \mathrm{mm} \mathrm{Hg}$ ), although the difference was not statistically different.

The coronary flow reserve (the ratio of peak to rest coronary blood flow velocity) was calculated for three arbitrary intervals of diastolic blood pressure. There was a variety of results, with no significant differences either within, or between, the control and hypertensive groups (diastolic pressure < $75 \mathrm{~mm} \mathrm{Hg}$ : $3.64 v$ 4.29; 75-100 mm Hg: 3.67 v 4.27; > $100 \mathrm{~mm} \mathrm{Hg}$ : 3.55 v 3.78).

If the assumption is made that the proportion of left ventricular myocardial flow supplied by the left coronary artery is the same in the control and hypertensive groups, an estimate of the coronary blood flow velocity (or volumetric flow)/g of left ventricular mass can be made. Figures 4 and 5 show the relation between diastolic blood pressure and coronary blood flow velocity corrected for echocardiographic left ventricular mass. Under resting conditions coronary blood flow velocity/gram tissue is relatively independent of blood pressure and there was a trend for lower values in the hypertensive group. In contrast, during peak hyperaemia, the slope of the coronary blood flow velocity/gram tissue/diastolic blood pressure relation was significantly reduced in the hypertensive group (analysis of covariance, $P<0.001)$. The incremental intracoronary

Figure 4 Relation between diastolic blood pressure $(D B P)$ and coronary blood flow velocity (CBFV)/unit of left ventricular ( $L V)$ mass in the control group. (Rest CBFV/unit mass $=$ $0.0142+$ $0.000347^{\star} D B P, r=$ $0 \cdot 296, P<0 \cdot 01$; peak $C B F$ Vlunit mass $=$ $0.0026+0.00199^{\star} D B P$ $r=0.561, P<0.001$ )

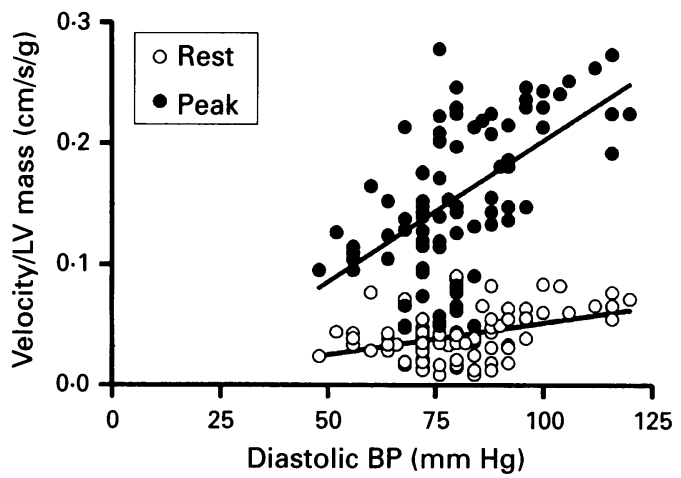

Figure 5 Relation between diastolic blood pressure (DBP) and pressure $(D B P)$ and
coronary blood flow velocity (CBFV)/unit of left ventricular (LV) mass in the hypertensive group. (Rest CBFVlunit mass $=$ $0.00943+$

$0.000174^{\star} D B P, r=$ $0 \cdot 000174^{\star} D B P, r=$
$0 \cdot 158$, not significant; peak CBFVlunit mass $=$ $0.0541+$

$0.000416^{\star} D B P, r=$ $0 \cdot 128$, not significant).

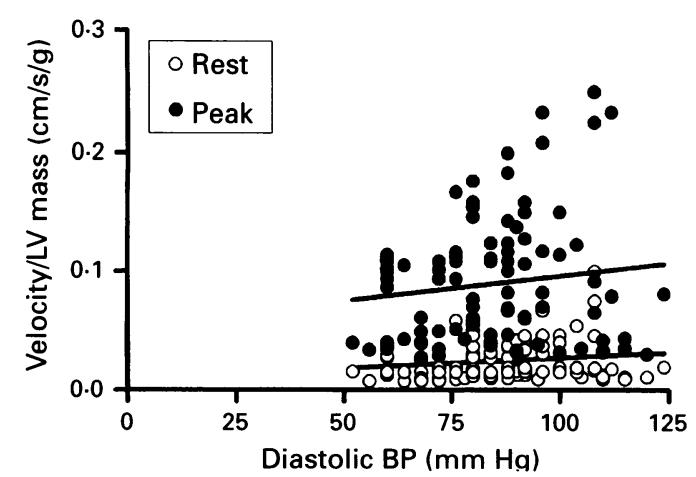

infusion of sodium nitroprusside was well tolerated. Resting coronary blood flow velocity remained unchanged at $6.5 \mathrm{~cm} / \mathrm{s}$ despite doses of up to $1 \mathrm{mg} / \mathrm{h}$. At baseline blood pressure, in the control and hypertensive groups (resting heart rate $75.5(13.9) \quad v \quad 69.2(11.6)$ beats/ $\mathrm{min}$ ), atrial pacing at $100 \mathrm{beats} / \mathrm{min}$ had minimal effect on resting (controls: paced 9.0 (3.4) $v$ unpaced $7 \cdot 6(3 \cdot 1) \mathrm{cm} / \mathrm{s}$; hypertensive group: $10.6(4 \cdot 7) v 9 \cdot 2(3.8) \mathrm{cm} / \mathrm{s})$ and peak coronary blood flow velocity (controls: $30 \cdot 2$ (9.5) v $29 \cdot 2$ $(9.6) \mathrm{cm} / \mathrm{s}$; hypertensive group: $30.9(12.6) v$ $32.9(11 \cdot 3) \mathrm{cm} / \mathrm{s})$. Atrial pacing was poorly tolerated by the two patients with hypertension and left ventricular dysfunction who responded with a decrease in diastolic blood pressure.

QUANTITATIVE CORONARY ANGIOGRAPHY

Figure 6 shows the repeatability of the technique for measurement of coronary vessel internal diameter. The difference in measured diameter is plotted against the average diameter. Intracoronary adenosine, in doses sufficient to cause maximal hyperaemia, produced little change in the diameter of the proximal left coronary system (fig 7). The incremental intracoronary infusion of sodium nitroprusside produced a parallel increase in vessel diameter, but the diameter change with the highest dose $(1 \mathrm{mg} / \mathrm{h})$ did not exceed the coefficient of repeatability for the measurement technique.

\section{VOLUMETRIC CORONARY FLOW}

Blood flow to the left coronary system at baseline blood pressure was calculated from the measured coronary blood flow. velocity and from quantitative angiographic data (table 2). Under resting conditions there was a trend for absolute blood flow to be greater in patients with hypertension, but during peak hyperaemia flow was similar in the two groups. Left coronary blood flow, corrected for echocardiographic left ventricular mass, was significantly lower in the hypertensive group at rest and during peak hyperaemia.

INFLUENCE OF LEFT VENTRICULAR GEOMETRY When the hypertensive group was subdivided using relative wall thickness, those with eccentric hypertrophy had increased systolic and diastolic wall stress (table 1). When compared with the control group, there was a trend for

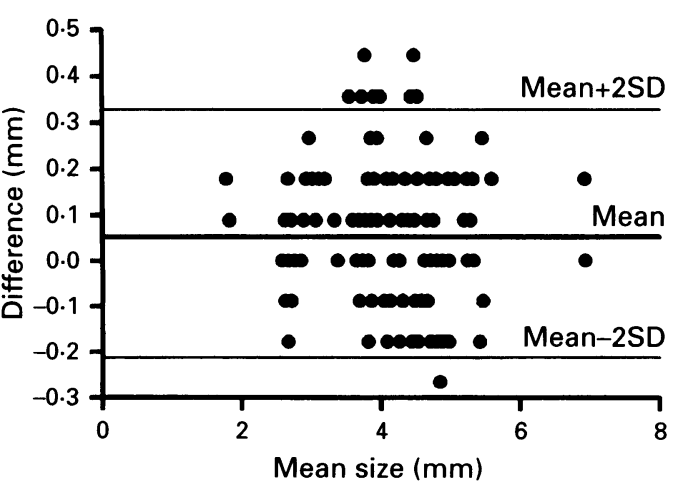

Figure 6 Repeatability of the technique used to measure coronary artery diameter (actual size). 


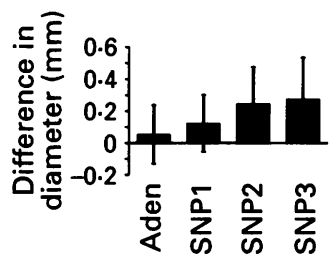

Figure 7 Effect of intracoronary injection of adenosine (Aden) and incremental intracoronary infusion of sodium nitroprusside (SNP1, $S N P 2$, and SNP3) on coronary arterial diameter. Columns represent mean values (SD). patients with concentric hypertrophy to have lower systolic and diastolic wall stress (table 1), similar resting and peak coronary blood flow, and a reduction in flow values corrected for left ventricular mass (table 2). Eccentric hypertrophy was associated with increased resting blood flow but flow/left ventricular mass was reduced because of the extent of hypertrophy.

\section{Discussion}

LEFT VENTRICULAR HYPERTROPHY AND CORONARY ARTERY DISEASE

A continuous relation between diastolic blood pressure and the risk of death from either coronary heart disease or stroke may be shown in the general population. For individuals with pre-existing coronary heart disease, a J shaped relation is apparent, with the lowest risk of coronary death occurring at the high $70 \mathrm{~s}(\mathrm{~mm}$ $\mathrm{Hg}$ ) diastolic pressure. The Framingham study convincingly showed that the presence of ECG or echocardiographic left ventricular hypertrophy is associated with an increased risk of cardiovascular events. ${ }^{30} 31$ When coronary heart disease and left ventricular hypertrophy coexist, the relation with diastolic pressure shifts to the right, with the J point in the mid to high $80 \mathrm{~s}(\mathrm{~mm} \mathrm{Hg}) .^{32}$

\section{PREVIOUS STUDIES INVOLVING ACUTE} HYPOTENSION

It might be reasonable to infer that studies of acute hypotension would show abnormalities most clearly in the presence of coronary heart disease. Indeed, Collins et al ${ }^{15}$ showed that patients with combined coronary heart disease and left ventricular hypertrophy had poor ventricular functional reserve, which was presumed to be linked to impaired coronary flow reserve.

Polese et $a l^{16}$ studied patients with hypertensive left ventricular hypertrophy, angina, and normal epicardial vessels. The results have been interpreted as indicating an upward shift of the lower range of coronary flow autoregulation to a perfusion pressure of about $90 \mathrm{~mm}$ $\mathrm{Hg}$ (corresponding to an aortic diastolic pressure of about $95 \mathrm{~mm} \mathrm{Hg}$ ), but have not been confirmed by others. While the study is strengthened by the demonstration of an increase in oxygen extraction below this criti- cal pressure, some inconsistencies are apparent on detailed appraisal of the results. For example, the observed increase in coronary sinus flow during acute hypotension in the control group is inadequately explained.

\section{PRESENT STUDY}

\section{Blood pressure}

Floras $^{13}$ suggested that antihypertensive treatment might exaggerate the normal nocturnal decrease in blood pressure to a level where autoregulation fails and myocardial ischaemia ensues. The present study shows a mean minimum diastolic pressure of $62 \mathrm{~mm} \mathrm{Hg}$ in the hypertensive group receiving treatment. It is conceivable that intermittent ambulatory recording may underestimate this effect, with the original study of Floras et al ${ }^{33}$ reporting mean invasive diastolic pressures as low as $\mathbf{3 0}$ $\mathrm{mm} \mathrm{Hg}$ in patients receiving $\beta$ blockers.

\section{Coronary blood flow velocity}

In the present study a Judkins Doppler catheter was used to examine left coronary blood flow velocity over the normal physiological range of blood pressures in patients with normal epicardial vessels and either atypical chest pain or hypertensive left ventricular hypertrophy. Resting coronary blood flow velocity remained relatively constant over a range of diastolic pressures in the control and hypertensive left ventricular hypertrophy groups, consistent with the concept of autoregulation (figs 2 and 3). Of particular note, no critical or threshold blood pressure could be determined in the hypertensive left ventricular hypertrophy group despite a reduction in diastolic pressure to as low as $50 \mathrm{~mm} \mathrm{Hg}$ in some patients.

A steep relation between hyperaemic (peak) coronary blood flow velocity and diastolic blood pressure was shown using adenosine to produce coronary vasodilatation, albeit with a wider scatter of results in the hypertensive left ventricular hypertrophy group, particularly at low blood pressures. This is in agreement with the animal work described by Mosher et $a l^{34}$ and the concept of coronary flow reserve elucidated by Hoffman. ${ }^{35}$ No previous clinical studies have documented paired observations (rest and peak hyperaemia) of coronary blood flow velocity over a range of perfusion pressures, and this emphasises the importance of inter-

Table 2 Variables used in the calculation of coronary blood flow

\begin{tabular}{|c|c|c|c|c|}
\hline & \multirow[b]{2}{*}{ Controls } & \multicolumn{3}{|c|}{ Patients with hypertensive $L V H$} \\
\hline & & All patients & $\begin{array}{l}\text { Concentric } \\
L V H\end{array}$ & $\begin{array}{l}\text { Eccentric } \\
L V H\end{array}$ \\
\hline $\begin{array}{l}\text { Rest } \\
\text { LMSA diameter (mm) } \\
\text { CBFV (cm/s) } \\
\text { Coronary flow }(\mathrm{ml} / \mathrm{min}) \\
\text { Coronary flow } / \mathrm{LV} \text { mass }(\mathrm{ml} / \mathrm{min} / \mathrm{g})\end{array}$ & $\begin{array}{c}4 \cdot 8(0 \cdot 4) \\
6 \cdot 4(2 \cdot 3) \\
83 \cdot 5(29 \cdot 5) \\
0 \cdot 38(0 \cdot 09)\end{array}$ & $\begin{array}{c}5 \cdot 4(0 \cdot 8) \\
8 \cdot 2(3 \cdot 2) \\
100 \cdot 6(27 \cdot 6) \\
0 \cdot 26(0 \cdot 09) \dagger\end{array}$ & $\begin{array}{c}6 \cdot 2(8 \cdot 6) \\
6 \cdot 6(1 \cdot 6) \\
93 \cdot 9(27 \cdot 5) \\
0 \cdot 28(0 \cdot 09)\end{array}$ & $\begin{array}{c}5 \cdot 1(4 \cdot 7,5 \cdot 5) \\
12 \cdot 2(13 \cdot 7,10 \cdot 7) \\
117 \cdot 2(113 \cdot 4,121 \cdot 1) \\
0 \cdot 20(0 \cdot 20,0 \cdot 21)\end{array}$ \\
\hline $\begin{array}{l}\text { Peak } \\
\text { LMSA diameter (mm) } \\
\text { CBFV (cm/s) } \\
\text { Coronary flow (ml/min) } \\
\text { Coronary flow } / \mathrm{LV} \text { mass }(\mathrm{ml} / \mathrm{min} / \mathrm{g})\end{array}$ & $\begin{array}{c}5 \cdot 0(0 \cdot 3) \\
33 \cdot 0(8 \cdot 8) \\
435 \cdot 6(76 \cdot 1) \\
2 \cdot 01(0 \cdot 23)\end{array}$ & $\begin{array}{c}5 \cdot 4(0 \cdot 9) \\
33 \cdot 3(6 \cdot 6) \\
419 \cdot 6(61 \cdot 0) \\
1 \cdot 16(0 \cdot 50) \ddagger\end{array}$ & $\begin{array}{c}6 \cdot 2(9 \cdot 0) \\
31 \cdot 3(6 \cdot 1) \\
435 \cdot 7(58 \cdot 5) \\
1 \cdot 36(0 \cdot 40)^{\star}\end{array}$ & $\begin{array}{c}5 \cdot 1(4 \cdot 8,5 \cdot 4) \\
38 \cdot 2(40 \cdot 0,36 \cdot 3) \\
372 \cdot 1(346 \cdot 2,398 \cdot 0) \\
0 \cdot 65(0 \cdot 61,0 \cdot 69)\end{array}$ \\
\hline
\end{tabular}


preting measurements of coronary flow reserve with reference to the diastolic (perfusion) pressure. Indeed, the critical information contained in figs 2 and 3 is diluted and lost by the arbitrary calculation of coronary flow reserve.

It would seem, therefore, that the behaviour of the coronary resistance vessels in response to changes in perfusion pressure may be similar in the hypertrophied and normal ventricle. If velocity/unit left ventricular mass is measured (figs 4 and 5), resting (autoregulated) values are similar in both patient groups, but during maximal vasodilatation the pressure velocity relation is less steep in the hypertensive than in the control group. This finding is indicative of impairment of maximal vasodilator function in the hypertrophy group despite the absence of a significant difference in coronary flow reserve calculated as the ratio of peak to resting velocity.

\section{Coronary blood flow}

The major epicardial (conductance) vessels are enlarged in animal models of pressure overloaded ventricular hypertrophy. ${ }^{36}$ No difference in the size of the proximal left coronary vessels between the control and hypertensive subjects could be determined in the present study. Therefore, the calculated coronary flow results are similar to those for coronary blood flow velocity. At baseline blood pressure, calculated absolute coronary flow (table 2) is consistent with increased resting flow in the hypertensive group and maximal hyperaemic flow similar to that in the control group. When absolute flow is standardised to left ventricular mass, relative flow is reduced in the hypertensive group at rest and during maximal vasodilatation.

\section{LIMITATIONS OF THE STUDY}

Given the incontrovertible evidence that left ventricular hypertrophy is associated with impaired coronary flow reserve, the difficulties in discerning differences in coronary blood flow velocity between the control and hypertensive left ventricular hypertrophy groups requires explanation.

\section{Patients}

Recruitment to the study was tempered by the high rate of occult carotid artery disease and difficulty in predicting the presence of coronary artery disease at angiography despite thallium scintigraphy. ${ }^{37}$ While coronary angiography was undertaken in the control

Table 3 Effects of variations in left and right coronary artery contribution to left ventricular (LV) myocardial blood flow

\begin{tabular}{lll}
\hline & Controls & Patients with hypertensive LVH \\
\hline Peak coronary flow (ml/min) & 400 & 400 \\
LV mass (g) & 200 & 400 \\
\multicolumn{2}{l}{ Calculated coronary blood flow (ml/min/g) } & \\
LV flow from left coronary artery & $2 \cdot 0$ & \\
100 & $2 \cdot 5$ & $1 \cdot 0$ \\
80 & 3.3 & $1 \cdot 25$ \\
60 & $4 \cdot 0$ & $1 \cdot 67$ \\
50 & $2 \cdot 0$ \\
\hline
\end{tabular}

Values are based on simplified data from tables 1 and 2 . LVH, left ventricular hypertrophy. group for a diagnosis of chest pain, unexplained by non-invasive investigation, it is possible that some of these patients may have had microvascular angina and consequent impairment of coronary flow reserve. In contrast to the study of Polese $e t a l,{ }^{16}$ patients continued their regular medication as it was considered important to assess the coronary circulation under stable physiological and pharmacological conditions.

\section{Measurement of coronary flow}

As coronary blood flow and vascular resistance were not measured in the study, care must be taken about inferences regarding autoregulation. The Judkins Doppler catheter provides a measure of blood flow velocity. Measurement of coronary blood flow required simultaneous assessment of the diameter of the proximal left coronary artery just distal to the catheter tip, corresponding to the range gate of the Doppler sample. Digital angiography was not available during this study, but single plane quantitative angiography performed by projection had an acceptable measurement error and suggested that neither adenosine nor sodium nitroprusside had significant effect on the diameter of the proximal left coronary arterial system.

Interpretation of the values for volumetric flow corrected for left ventricular mass must be cautious, as we have made no allowance for the contribution of the right coronary artery flow to the left ventricular myocardium, and have presumed that the relative proportions of left and right coronary artery flow to the left ventricle are equal in the control and hypertrophy groups. Coronary angiography showed dominance of the right coronary artery in 14 of 15 patients, but it is known that there is about $50 \%$ overlap in the territories supplied by the left and right coronary arteries, particularly in the inferoposterior region. ${ }^{38}$ Table 3 gives the quantitative impact of variations in the percentage of peak left ventricular blood flow supplied by the left coronary artery using simplified data. An enormous systematic difference in the proportion of the left ventricular flow from the left coronary artery would be necessary to account for the differences in calculated "peak flow/left ventricular mass" on a basis other than a real difference in coronary flow/g tissue between the control and hypertrophied groups. Given the increase in interstitial fibrosis associated with severe left ventricular hypertrophy, however, we cannot estimate from the current data the reduction in coronary blood flow to the myocytes of the left ventricle.

While myocardial oxygen consumption could not be determined in this study, the calculated decrease in systolic wall stress in patients with concentric hypertrophy may have contributed to the observed reduction in resting coronary flow/left ventricular mass in the hypertensive group (table 2 ). The contribution of extravascular compressive forces to the abnormal coronary haemodynamics, as well as the role of primary microvascular abnormalities, whether structural ${ }^{78}$ or due to impaired 
endothelium dependent control, ${ }^{10}$ requires further investigation

The technique of coronary sinus thermodilution, as used by Polese et al, ${ }^{16}$ may not reliably determine small changes $(<30 \%)$ in coronary flow, ${ }^{39}$ or detect rapid changes in coronary flow such as that associated with coronary hyperaemia in response to adenosine. While the Doppler technique has proven sensitive to rapid changes in flow and is reproducible, prolonged cardiac catheterisation procedures may not be performed without some risk. It would be prudent to recommend that contrast transoesophageal echocardiography be used to assess left main stem flow velocity non-invasively when the epicardial vessels are known to be normal, ${ }^{40}$ and to consider the use of the Doppler guidewire to measure coronary blood flow velocity in the presence of coronary artery disease..$^{41}$ Coronary flow reserve in dogs is lower in subendocardial than subepicardial muscle. ${ }^{42}$ The Judkins Doppler catheter measures global left ventricular flow and gives no indication of transmural changes that may be particularly important in exercise induced ischaemia.

In conclusion, the results are consistent with an inadequate blood supply to the hypertrophied heart, but no upward shift of the lower end of autoregulatory range was observed.

We acknowledge the support and cooperation of Professor AR Lorimer. DRW was supported by a British Heart Foundation Lorimer. DRW was supported by a British H
Friends Provident Junior Research Fellowship.

1 Strauer BE. Myocardial oxygen consumption in chronic heart failure: role of wall stress, hypertrophy and coronary reserve. Am F Cardiol 1979;44:730-40.

2 Houghton JI, Frank M, Carr A, Von Dohlen T, Prisant M. Relations among impaired coronary flow reserve, left ventricular hypertrophy and thallium perfusion defects in hypertensive patients without obstructive coronary artery disease. 7 Am Coll Cardiol 1990;15:43-51.

3 Opherk D, Mall G, Zebe H, Schwarz F, Weihe E, Manthey J, et al. Reduction of coronary reserve: a mechanism fo angina pectoris in patients with arterial hypertension and normal coronary arteries. Circulation 1984;69:1-7.

4 Brush JE, Cannon RE III. Schenke WH, Bonow RO, Leon $\mathrm{MB}$, Maron BJ, et al. Angina due to coronary microvascular disease in hypertensive patients without left ventricular hypertrophy. N Engl ₹ Med 1988;319:1302-7.

5 Vogt M, Motz W, Strauer BE. Coronary haemodynamics in hypertensive heart disease. Eur Heart $\mathcal{f}$ 1992;13(supp D):44-9.

6 Aguirre JM, Rodriguez E, Ruiz de Azua E, Urrengoetxea J, Faus JM, Caso R, et al. Segmental coronary reserve in hypertensive patients with echocardiographic left ventricular hypertrophy, gamma-graphic ischaemia and normal

coronary angiography. Eur Heart f 1993;14(suppl]):25-31. nauer $S$, Motz W, Strauer BE. reduced coronary reserve in hypertensive heart disease. reduced coronary reserve in
Circulation $1991 ; 84$ (suppl):479.

8 Kanatsuka H, Lamping KG, Eastham CL, Marcus ML, Dellsperger KC. Coronary microvascular resistance in Dellsperger KC. Coronary microvascular

9 Lindner L, Kiowski W, Buhler F, Luscher TF. Indirect evidence for release of endothelium-derived relaxing factor in human forearm circulation in vivo. Blunted response in human forearm circulation in vivo. Blunted respons

10 Panza JA, Quyyumi AA, Brush JE Jr, Epstein SE. Abnormal endothelium-dependent vascular relaxation in patien with arterial hypertension. $N$ Engl $\mathcal{F}$ Med 1990;323:22-7.

11 Weber KT, Brilla CG. Pathological hypertrophy and cardiac interstitium. Fibrosis and renin-angiotensin-aldosterone system. Circulation 1991;83:1849-65.

12 MacMahon S, Peto R, Cutler J, Collins R, Sorlie P, Neaton J, et al. Blood pressure, stroke, and coronary heart disease. Part 1-prolonged differences in blood pressure: prospective observational studies corrected for regression dilution bias. Lancet 1990;335:765-74.

13 Floras JS. Antihypertensive therapy, myocardial infarction and nocturnal myocardial ischaemia. Lancet 1988;ii:994-6.

14 Pepi M, Alimento M, Maltagliati A, Guazzi MD. Cardiac hypertrophy in hypertension. Repolarization abnormalities elicited by rapid lowering of blood pressure. Hypertension 1988;11:84-91.

15 Collins P, Cruickshank JM, Keegan J, Fox K. Acute blood pressure reduction causes an impairment of left ventricular function in hypertensive patients with coronary heart disease and left ventricular hypertrophy [abstract]. Eur Heart $\mathcal{F}$ 1991;12Suppl:242.

16 Polese A, De Cesare N, Montorsi P, Fabbiocchi F, Guazzi M, Loaddi A, et al. Upward shift of the lower range of coronary flow autoregulation in hypertensive patients with hypertrophy of the left ventricle. Circulation 1991;83: 845-53.

17 Macfarlane PW, Macfarlane DK, Podolski M, Lawrie TDV. The ECG analysis programme for the Mingocare system. Electromedica 1984;52:126-36.

18 Macfarlane PW, Watts MP, Podolski M, Shoat D, Lawrie TDV. The new Glasgow system. In: Williams $\mathrm{JL}$, van Bemmel JH, Zyweitz C, eds. Computer ECG analysis: towards standardisation. Amsterdam: Elsevier, 1986:31-6.

19 Sahn DJ, Demaria A Kisslo J, Weyman A Recom mendations regarding quantitation in $\mathbf{M}$-mode echocarmendations regarding quantitation in M-mode echocar-
diography: results of a survey of echocardiographic diography: results of a survey of echocard

20 Devereux RB, Reichek N. Electrocardiographic determination of left ventricular mass in man: anatomical validation of the method. Circulation 1977;55:613-8.

21 Devereux RB, Lutas EM, Casale PN, Kligfield P, Eisenberg $\mathrm{RR}$, Hammon IW, et al. Standardisation of $M$ Mode echocardiographic left ventricular anatomic measurements. F Am Coll Cardiol 1984;4:1222-30.

22 McDonald IG, Feigenbaum H, Chang S. Analysis of left ventricular wall motion by reflected ultrasound. Application to assessment of myocardial function. Circulation 1972;46:14-25.

23 Savage DD, Garrison RJ, Kannel WB, Levy D, Anderson SJ, Stokes J, et al. The spectrum of left ventricular hypertrophy in a general population sample: the Framingham study. Circulation 1987;75(suppl I):26-33.

24 Grossman W, Jones D, McLaurin LP. Wall stress and patterns of hypertrophy in the human left ventricle. $f$ Clin Invest $1975 ; 56: 56-64$

25 Graettinger WF, Lipson JL, Cheung DG, Weber MA. Validation of portable blood pressure monitoring devices: comparisons with intra-arterial and sphygmomanometer measurements. Am Heart f 1988;116:1155-60.

26 Martin W, Tweddel AC, McGhie AI, Hutton I. Gated thallium scintigraphy in patients with coronary artery disease an improved planar imaging technique. Clin Phys Physiol Meas 1987;8:343-54.

27 Kern MJ. A simplified method to measure coronary blood flow velocity in patients: validation and application of a Judkins-style Doppler-tipped angiographic catheter. $A m$ Heart f 1990;120:1202-12.

28 Wilson RF, Wyche K, Christensen BV, Zimmer S, Laxson DD. The effect of adenosine on human coronary circulation. Circulation 1990;82:1595-606.

29 Bland JM, Altman DG. Statistical methods for assessing agreement between two methods of clinical measurement. agreement between two

30 Kannel WB, Gordon T, Castelli WP, Margolis JR. Electrocardiographic left ventricular hypertrophy and risk of coronary heart disease: the Framingham study. Ann Intern Med 1970;72:813-22.

31 Levy D, Garrison RJ, Savage DD, Kannel WB, Castelli WP Prognostic implications of echocardiographically determined left ventricular mass in the Framingham heart study. $N$ Engl $\mathcal{F}$ Med 1990;322:1561-6.

32 D'Agostino RB, Belanger AJ, Kannel WB, Cruickshank JM Relation of low diastolic blood pressure to coronary heart disease in the presence of myocardial infarction. $B M F$ 1991;303:385-9.

33 Floras JS, Jones JV, Hassan MO, Sleight P. Ambulatory blood pressure during once-daily randomised doubleblind administration of atenolol, metoprolol, pindolol, and blind administration of atenolol, metoprolol, pindolol,
slow-release propranolol. $B M 71982 ; 285: 1387-92$.

34 Mosher P, Ross J Jr, McFate PA, Shaw RF. Control of coronary blood flow by an autoregulatory mechanism. Circ Res 1964;14:250-9.

35 Hoffman JIE. A critical view of coronary reserve. Circulation 1987;75(suppl I):I6-I11

36 Stack RS, Rembert JC, Schirmer B, Greenfield JC. Relation of left ventricular mass to geometry of the proximal coronary arteries of the dog. Am $\mathcal{f}$ Cardiol 1983;51:1728-31.

37 Pringle SD, Dunn FG, Tweddel AC, Martin W, Macfarlane $\mathrm{PW}$, McKillop JH, et al. Symptomatic and silent myocardial ischaemia in hypertensive patients with left ventricular hypertrophy. Br Heart $\mathcal{f}$ 1992;67:377-82.

38 Martin W, Tweddel AC, Hutton I. Flow and distribution response to stress in normal coronary arteries [abstract]. $\mathcal{F}$ Nucl Med 1987;30:818.

39 Marcus ML, Wilson RF, White CW. Methods of measurement of myocardial blood flow in patients: a critical ment of myocardial blood flow in
review. Circulation 1987;76:245-53.

40 Yamagishi $M$, Miyatake K, Beppu S, Kumon K, Suzuki S, Tanaka N, et al. Assessment of coronary blood flow by transesophageal two-dimensional pulsed Doppler echocardiography. Am $\mathcal{F}$ Cardiol 1988;62:641-4

41 Doucette JW, Corl D, Payne HM, Flynn AE, Goto M, Nassi $\mathbf{M}$, et al. Validation of a Doppler guide wire for intravascular measurement of coronary artery flow velocity. Circulation 1992;85:1899-911.

42 Rembert JC, Kleinman LH, Fedor JM, Wechsler AS, Greenfield JC. Myocardial blood flow distribution in concentric left ventricular hypertrophy. $\mathcal{F}$ Clin Invest 1978;62 379-86. 